\title{
BMJ Open Physicians' characteristics and practices associated with the provision of cancer screening advice to their patients: the Spanish SUN cohort study
}

Carmen Sayon-Orea, ${ }^{1,2}$ Silvia Carlos (D) ,,2 Anaïs Rico-Campà, ${ }^{1}$
Alejandro Fernández-Montero (1D , , ${ }^{2,3}$ Carmen de la Fuente-Arrillaga, ${ }^{1,2}$
Estefanía Toledo, ${ }^{1,2}$ Stefanos Kales, ${ }^{4}$ Miguel Angel Martínez-González,
To cite: Sayon-Orea C, Carlos S, Rico-Campà $A$, et al. Physicians' characteristics and practices associated with the provision of cancer screening advice to their patients: the Spanish SUN cohort study. BMJ Open 2022;12:e048498. doi:10.1136/ bmjopen-2020-048498

- Prepublication history and additional supplemental material for this paper are available online. To view these files, please visit the journal online (http://dx.doi.org/10.1136/ bmjopen-2020-048498).

Received 28 December 2020 Accepted 03 December 2021

\section{Check for updates}

(c) Author(s) (or their employer(s)) 2022. Re-use permitted under CC BY-NC. No commercial re-use. See rights and permissions. Published by BMJ.

${ }^{1}$ Preventive Medicine and Public Health, University of Navarra, Pamplona, Spain

${ }^{2}$ Instituto de Investigación Sanitaria de Navarra, IdiSNA, Pamplona, Spain

${ }^{3}$ Occupational Medicine, University of Navarra, Pamplona, Navarra, Spain

${ }^{4}$ Environmental Health, Harvard University T.H. Chan School of Public Health, Boston, Massachusetts, USA

Correspondence to

Dr Silvia Carlos;

scarlos@unav.es

\section{ABSTRACT}

Objectives To evaluate the association between cancer screening counselling provided by medical doctors to their patients and each doctor's own anthropometrics, lifestyle, cancer screening practices, and personal and family history of cancer.

Design Prospective cohort study.

Setting Substudy including physicians participating in a Spanish cohort study with open enrolment.

Participants Among 22800 participants in the cohort as of May 2018, there were 2371 physicians who had replied to the cohort baseline questionnaire, had an email account and were younger than 65 years (retirement age in Spain). From this subsample, 890 replied to an online questionnaire focused on their clinical practices related to the counselling provided to their patients and to their prescription practices of preventive medications. Their mean age was 51.7 (SD 9.4) years and 48\% were women. Outcome measures Frequency of counselling given to their patients on specific practices of breast, colorectal and prostate cancer screenings.

Results Counselling on cancer screening to their patients was provided by $65 \%$ of physicians in a scenario of colorectal cancer, $59 \%$ for prostate cancer and $58 \%$ for breast cancer. More frequent cancer screening counselling was associated with the specialties of family medicine $(\mathrm{OR}=9.4,95 \% \mathrm{Cl} 5.1$ to 17.1$)$ and internal medicine ( $O \mathrm{R}=2.9,95 \% \mathrm{Cl} 1.5$ to 5.7 ) as compared with other specialties. Recommending cancer screening was associated with more frequent counselling on smoking cessation ( $\mathrm{OR}=3.7,95 \% \mathrm{Cl} 2.6$ to 5.4$)$, having personally attended colorectal cancer screening $(\mathrm{OR}=2.2,95 \% \mathrm{Cl}$ 1.1 to 4.7$)$ and prescribing blood pressure medication more often than their colleagues $(\mathrm{OR}=2.1,95 \% \mathrm{Cl} 1.2$ to 3.7).

Conclusions Among medical doctors, cancer screening counselling was provided to their patients more frequently for doctors with family medicine or internal medicine specialties and for physicians who regularly offered counselling on certain lifestyle behaviours, and those having personally attended colorectal cancer screening. Doctors' own personal practices and knowledge of healthy lifestyles may help doctors to more frequently provide counselling on cancer screening to their patients.

\section{Strengths and limitations of this study}

- This study evaluates the association between doctors' own lifestyle and clinical practice in association with their patient counselling on cancer screening exercise, an association that has been scarcely explored in the literature.

- All physicians included come from the Seguimiento Universidad de Navarra study, a cohort that collects abundant information regarding lifestyles and the occurrence of many chronic diseases.

- Changes in anthropometrics, sociodemographics and behaviours that may have occurred during the follow-up were not taken into account.

- Characteristics of patients who were counselled by the physicians included in the study were not collected; these characteristics might be a factor to modify the frequency and the content of counselling.

- Fourteen per cent of the physicians included in the study were not attending patients at study time; in that case, we asked what they would have done if they were attending.

\section{INTRODUCTION}

Cancer is the second leading cause of death worldwide after cardiovascular disease. ${ }^{1}$ According to estimates from the Global Cancer Observatory, in 2018, 18.1 million new cancer cases and nearly 10 million cancer deaths occurred worldwide. Breast, lung, colorectal and prostate cancers are the most common cancers around the world, and among them, lung and colorectal cancers are the most common causes of cancer death. ${ }^{2}$

Cancer secondary prevention (early detection with screening programmes) contributes to cancer control. ${ }^{3}$ Notwithstanding, as commented by some European authors, the enthusiasm about secondary prevention has been tempered. ${ }^{4}$ However, taking part in organised cancer screening programmes (such as bowel, breast and cervical) is among 
the 12 ways to reduce cancer risk proposed by the European Code Against Cancer. ${ }^{6}$

Currently, in Spain, breast and colorectal screening programmes are population-based programmes, and cervical cancer screening, which has been opportunistic, is now beginning to be included as a population-based programme in some Spanish regions. Based on the National Health Survey 2017, 95\% of women 50-69 years had ever attended a breast cancer screening (although coverage varied for the different regions), and only $29 \%$ of the population aged 50-69 had been tested with colorectal cancer faecal occult blood test.

Health promotion is an important task in daily clinical practice especially among general practitioners. Focusing on short messages containing these recommendations would be a useful way to reduce the burden of cancer.

Physicians are known to be aware of cancer screening counselling, but some practitioner-specific obstacles or barriers may avoid a correct provision of pertinent counselling, ${ }^{7}$ including the lack of time during the visit, distraction by competing health problems and inadequate training of doctors. In this context, a continued study of the obstacles and ways to overcome them could have a great potential to improve rates of counselling on cancer prevention. ${ }^{7}$ In this line, a recent study investigated the perceived barriers in relation to screening for cancer, and the authors highlighted the need for more physician education on screening programmes and screening guidelines. The results of that study suggested the need to improve awareness and adherence to screening guidelines and recommended practices. ${ }^{8}$

Moreover, the identification of personal doctor-related factors, associated with the provision of adequate counselling on cancer screening practices, deserves further investigation. Our main hypotheses were that (1) personal screening practices followed by medical doctors and personal cancer history of medical doctors may predict whether or not they provide counselling on cancer screening to their patients; (2) medical doctors who more frequently give advice on smoking cessation and healthy nutrition to their patients are more likely to also encourage their patients to comply with recommended screening practices; and (3) among medical specialties, the provision of counselling is more frequent.

The aim of this study was to evaluate among doctors participating in the Spanish Seguimiento Universidad de Navarra (SUN) cohort, the association of cancer screening counselling to their patients within their specialty, and with their own anthropometrics, lifestyles, history of cancer, cancer screening and clinical practice.

\section{METHODS}

\section{Design and sample}

This is a substudy within the SUN prospective cohort study. The objectives, design and methods of the SUN cohort have been published in detail elsewhere. ${ }^{9-13}$ Briefly, this cohort began in 1999 and included university graduates from the University of Navarra and other Spanish universities. The recruitment is permanently open, and the main objective was to assess the effects of diet and lifestyles on chronic diseases.

In this substudy, we included physicians who were participating in the SUN cohort up to May 2018, excluding those without an email and those older than 65 years (retirement age in Spain).

\section{Data collection}

All participating physicians had replied to the SUN study baseline questionnaire $\left(\mathrm{Q}^{0}\right)$, which gathers sociodemographics, anthropometrics, lifestyle and diet (a validated 136-item semiquantitative Food Frequency Questionnaire). ${ }^{14-16}$ It also collects data on personal and familial cancer history, diagnosis of different diseases and attendance to screening tests (including mammography, colorectal/sigmoid, cervical and prostate cancers).

In this substudy, we sent medical doctors participating in the SUN cohort a short additional online questionnaire focused on their clinical practices related to the counselling provided to their patients and to their prescription practices of preventive medications. Doctors were asked whether they were currently providing clinical care (at study time); otherwise, they were asked to answer the questionnaire as if they were. The physicians' specialty was collected as a categorical variable with up to 44 options and an additional 'other' category.

Medical doctors participating in the study were asked about the percentage of patients that they counselled on mammography (women aged 50-70 years), colorectal cancer (people aged 50-75 years) and prostate cancer (men aged 50-75 years) $(0 \% /<20 \% / 20 \%-39 \% / 40 \%-$ $59 \% / 60 \%-69 \% / 70 \%-99 \% / 100 \%)$. They were also asked about the time spent in each counselling session $(0>0$ $<5 / 5-9 / 10-14 / 15-29 / \geq 30 \mathrm{~min} /$ patient). Regarding prescribing drugs for preventing chronic diseases or treating risk factors for chronic diseases, they had three possible answers: 'less/equal/more' than their colleagues.

In order to improve response rates, up to three reminders were sent by email.

Data from the doctors' questionnaire were merged with their baseline data on their own lifestyles and their personal practices of screening and personal and familial history of cancer, taking into account their age and sex. Doctors answering the questionnaire on counselling of their patients were not informed of the hypotheses of this study.

\section{Statistical analysis}

First, univariate analyses were carried out to describe the doctors' (1) sociodemographics; (2) professional characteristics: specialty, as the main specialties were family medicine $(24 \%)$ and internal medicine $(11 \%)$, the variable was categorised as 'family medicine/internal medicine/others'; currently attending patients 'yes/no'; (3) counselling practices (counselling patients on smoking cessation/avoidance, exercise, weight control, nutrition, 
alcohol avoidance/moderate consumption and cancer screening); (4) prescribing practices of preventive medications (vitamins, blood pressure medication, lipid-lowering drugs, osteoporosis drugs, hormone replacement therapy and aspirin); (5) body mass index (BMI) ('normal weight': $<25 \mathrm{~kg} / \mathrm{m}^{2}$, 'overweight': $25-30 \mathrm{~kg} / \mathrm{m}^{2}$, and 'obesity': $\left.>30 \mathrm{~kg} / \mathrm{m}^{2}\right)$; (6) health-related behaviours: MedDiet adherence (considering the 0-9 Trichopoulou score categorised as $0-2,3-5$ and $6-9$ ); physical activity (Metabolic Equivalent of Task (METs), tertiles), smoking (never/former/current), alcohol consumption (g/day) (for women and men: $<5$ or $<10 / 5-25$ or $10-50 />25-$ 125 or $>50-125$, respectively); (7) history of cancer; (8) cancer prevalence; and (9) personal attendance to cancer screening programmes.

Second, crude logistic regression analyses were done to evaluate the association between counselling patients on specific practices of breast, colorectal and prostate cancer screenings ( $\%$ of patients counselled, categorised as $0=0-<60 \%$ and $1=60 \%-100 \%$ ) and all the independent variables analysed in the descriptive analyses (doctors' sociodemographics, clinical practices, baseline lifestyles, familial and personal cancer history, and their passive attendance to cancer screening).

Finally, a multivariate logistic regression analysis was carried out to analyse the adjusted association between cancer screening counselling and doctors' baseline characteristics and clinical practices. Each independent characteristic was adjusted for all other variables: age, sex, specialty, providing clinical care, counselling on nutrition, counselling on physical activity, counselling on smoking cessation, family history of cancer, cancer diagnosis and passive attendance to colonoscopy, and for female physicians, an additional adjustment for passive attendance to Papanicolaou and mammography was included.

All $\mathrm{p}$ values were two-tailed; a $\mathrm{p}$ value of $<0.05$ was considered statistically significant. Statistical analyses were done with Stata V.12.0.

\section{Patient and public involvement}

Patients were not involved in this study.

\section{RESULTS}

Among 22800 participants in the SUN cohort in May 2018, 2371 medical doctors met our inclusion criteria. We collected data from 890 of them, with a $37 \%$ response rate $(890 / 2371)$. The mean time in the cohort since their Q0 was 13.1 (SD 3.9) years.

Table 1 shows the main sociodemographic characteristics and clinical practice of physicians. Their mean age was 51.7 (SD 9.4) years and $48 \%$ were women. The main specialties were family medicine $(24 \%)$ and internal medicine $(11 \%)$. Most of the participating doctors (86\%) were involved in clinical care at study time.

Regarding their clinical practice related to cancer screening counselling, overall, $65 \%$ of doctors reported any counselling on colorectal cancer screening (for patients $50-75$ years), $59 \%$ on prostate cancer screening (men aged $50-75$ years) and $58 \%$ on mammography (women aged 50-70 years). When we evaluated the doctors who frequently counselled (60\% or more) their patients on these cancer screening practices, the percentages were $33 \%$ for colorectal cancer, $25 \%$ for prostate cancer and 30\% for mammography. Regarding the time spent on screening counselling for each patient, only $11 \%$ of doctors spent more than 5 min counselling on screening of colorectal cancer, $7 \%$ counselling on prostate cancer screening and $7 \%$ on mammography.

When we analysed the doctors' sociodemographics and clinical practices that were associated with cancer screening counselling (table 1) in an initial crude regression, we found that there was no significant association between physicians' sex with cancer screening counselling. Globally, family medicine and internal medicine specialists were significantly more likely than other specialists to counsel on cancer screening (online supplemental table 1). We observed that, overall, counselling patients on healthy behaviours was strongly associated with cancer screening counselling. Most doctors (73\%) counselled $60 \%-100 \%$ of their patients on smoking cessation, and around half of them counselled most of their patients on other behaviours, such as exercise, weight/ nutrition and alcohol avoidance. Doctors who compared their own practices with other colleagues more frequently prescribed blood pressure medication (14\%), lipidlowering drugs (13\%), osteoporosis drugs (13\%) and, in general, significantly more likely to counsel on cancer screening (table 1).

When we analysed the doctors' own baseline anthropometrics and lifestyle (table 2), we observed that in the crude analysis, neither being overweight/obese at baseline nor reporting high MedDiet adherence, physical activity, alcohol consumption or smoking was significantly associated with cancer screening counselling practices. Only doctors who had been former smokers, compared with doctors who had never smoked, were significantly more likely to counsel on mammography $(\mathrm{OR}=1.6$, 95\% CI 1.1 to 2.2 ).

Overall, at baseline, $24 \%$ of the doctors reported familial cancer history and $5 \%$ reported having had themselves a cancer diagnosis. Among the 428 female doctors, $71 \%$ had been screened with Papanicolau and $39 \%$ had undergone a mammography, and among all doctors, $15 \%$ had attended a colonoscopy. Neither doctors reporting a family history of cancer nor those having had a personal cancer diagnosis were significantly more likely to counsel on cancer screening (table 2). However, for female doctors, having attended a mammography was significantly associated with higher frequency of counselling on mammography to their patients $(\mathrm{OR}=1.7,95 \%$ CI 1.1 to 2.5).

When a multivariate model was fitted to evaluate the variables associated with counselling on overall cancer screening (figure 1), we found that the specialties family medicine $(\mathrm{OR}=9.4,95 \%$ CI 5.1 to 17.1$)$ and internal medicine 
Table 1 Frequency of cancer screening counselling and crude association with doctors' sociodemographics and clinical practice $(\mathrm{N}=890)$

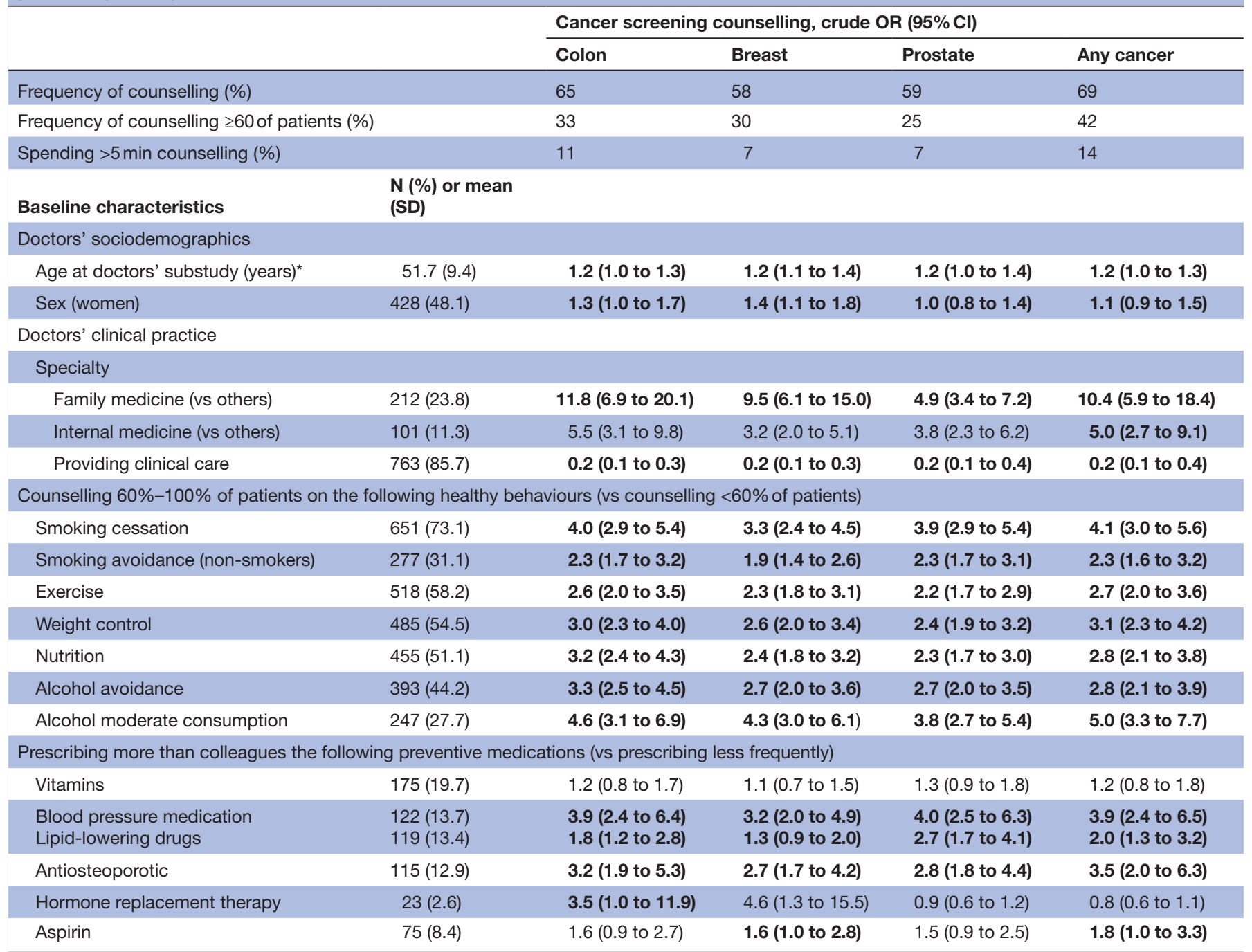

Values boldfaced are those with statistically significant $\mathrm{p}$ values.

*OR for 10 years of increment.

$(\mathrm{OR}=2.9,95 \%$ CI 1.5 to 5.7$)$ as compared with the rest of specialties, prescribing blood pressure medication more than their colleagues $(\mathrm{OR}=2.1,95 \%$ CI 1.2 to 3.7$)$, counselling on smoking cessation (OR=3.7, 95\% CI 2.6 to 5.4) and that the doctor personally attended a colorectal cancer screening programme $(\mathrm{OR}=2.2,95 \%$ CI 1.1 to 4.7$)$ were factors directly associated with more frequently counselling their patients on cancer screening practices. Doctors currently providing clinical care, compared with doctors not currently involved in clinical care (they responded based on their previous experience as doctors) were significantly less likely to counsel on cancer screening.

\section{DISCUSSION}

Our results show that among a subset of doctors participating in the SUN cohort, some clinical practices and lifestyles, and personal and family history of diseases were associated with cancer screening counselling. Family medicine and internal medicine specialties, counselling on healthy behaviours, prescribing preventive medications, being former smokers and having previously attended a colonoscopy were independently associated with providing cancer screening counselling.

Overall, nearly $70 \%$ of the doctors included in the study reported any counselling on cancer screening (breast, colorectal or prostate). Similar to our results, Siembida et al found that over $80 \%$ of the physicians receiving reminders and $65 \%$ of those not receiving reminders recommended breast screening to women between 40 and 74 years. It needs to be noted that the physicians included in that study were only those who were providing primary care or general gynecological care. ${ }^{17}$ Radhakrishnan et al carried out a study including 2000 doctors (Internal medicine, family medicine and gynaecology) and found that around $80 \%$ of them recommended breast cancer screening to women with no family history of 
Table 2 Doctors' baseline lifestyle, familial and personal cancer history, and their passive attendance to cancer screening and their crude association with cancer screening counselling $(\mathrm{N}=890)$

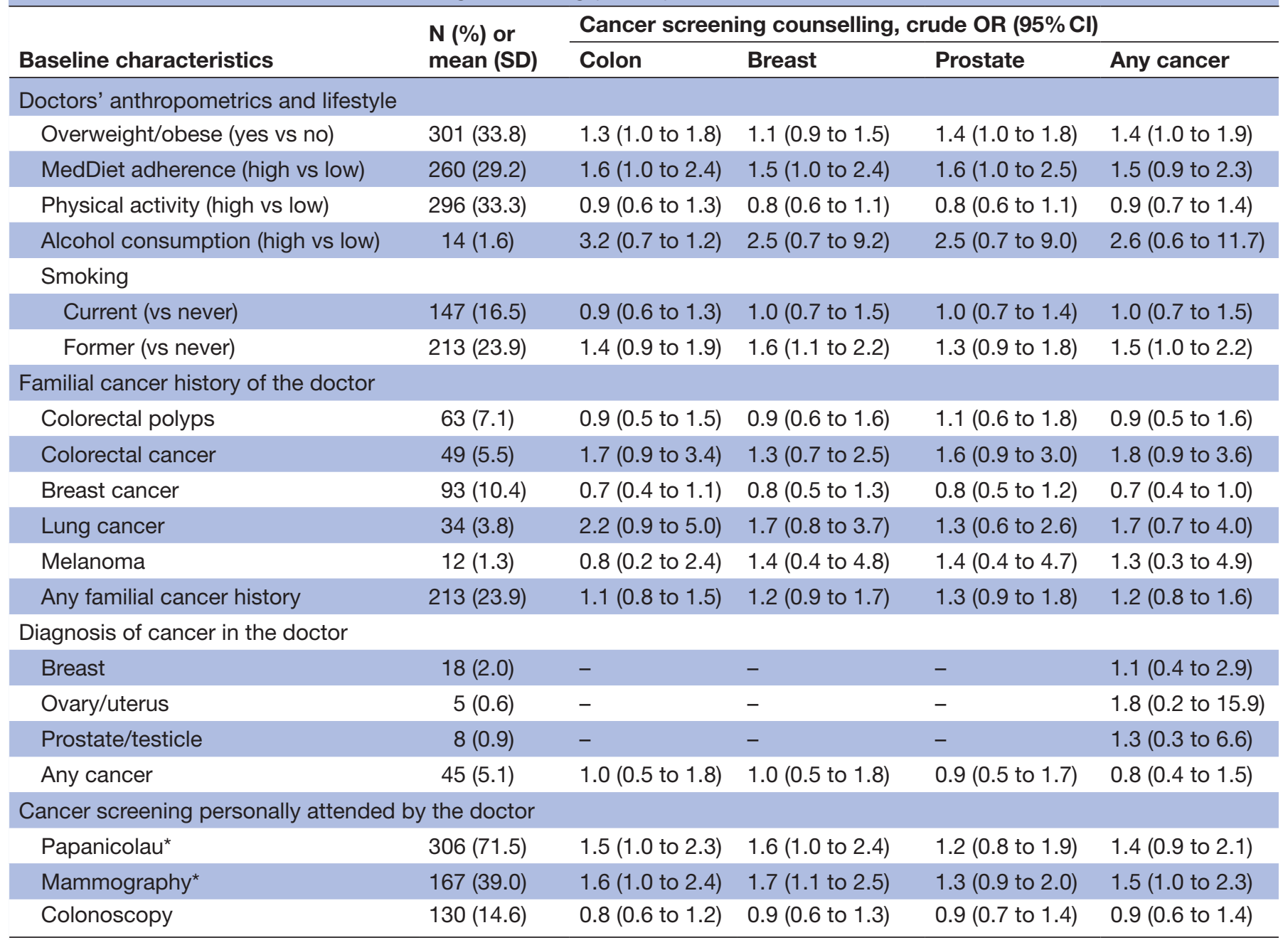

${ }^{*}$ Among 428 female doctors in the study.

breast cancer. ${ }^{18}$ As Grady and Redberg showed, those physicians might not be representative of US primary care physicians, ${ }^{19}$ but in any case, based on the figures shown, we can affirm that cancer screening counselling among doctors can be considered quite frequent. The Council of the European Union and the US Preventive Services Task Force (USPSTF) recommend populationbased screening only for breast, cervical and colorectal cancers using evidence-based methods with quality assurance of the entire screening process. ${ }^{20} 21$ Currently, in Spain, breast and colorectal screening programmes are population-based. Attending these programmes is usually a result of an invitation to a target population to participate in the screening programme. However, it is known that the physician's recommendation is a strong predictor of colorectal cancer screening participation rate. $^{22}$ In this line, data from the last National Health Survey in Spain in 2017, ${ }^{23}$ regarding breast and colorectal cancer screening, show that $28 \%$ of the women and $26 \%$ of men who attended these programmes were a result of medical counselling. This information shows that cancer screening counselling, especially by primary care doctors, is a good strategy to increase participation in screening programmes. Primary care physicians are critical to counselling patients on cancer prevention and screening. ${ }^{1824-27}$ In this way, our results show that family medicine doctors were more likely to counsel on cancer screening, as reported by Kepka et al, who found that patients who saw a primary care physician were more likely to be compliant with cervical, breast and colorectal cancer screenings. ${ }^{28}$ Regarding prostate cancer screening, the recommendations for men aged 55-69 years by the USPSTF on a Prostate Specific Antigen (PSA)-based screening, which has been reported to have both potential benefits and harms, state that the decision to undergo periodic PSA-based screening for prostate cancer should be an individual one and should include the discussion of potential benefits and harms of screening with their clinician. Thus, clinicians should not systematically screen men who do not express a preference for screening after being informed and understood the benefits and risks ( $\mathrm{C}$ recommendation), whereas for older men ( $\geq 70$ years), screening 


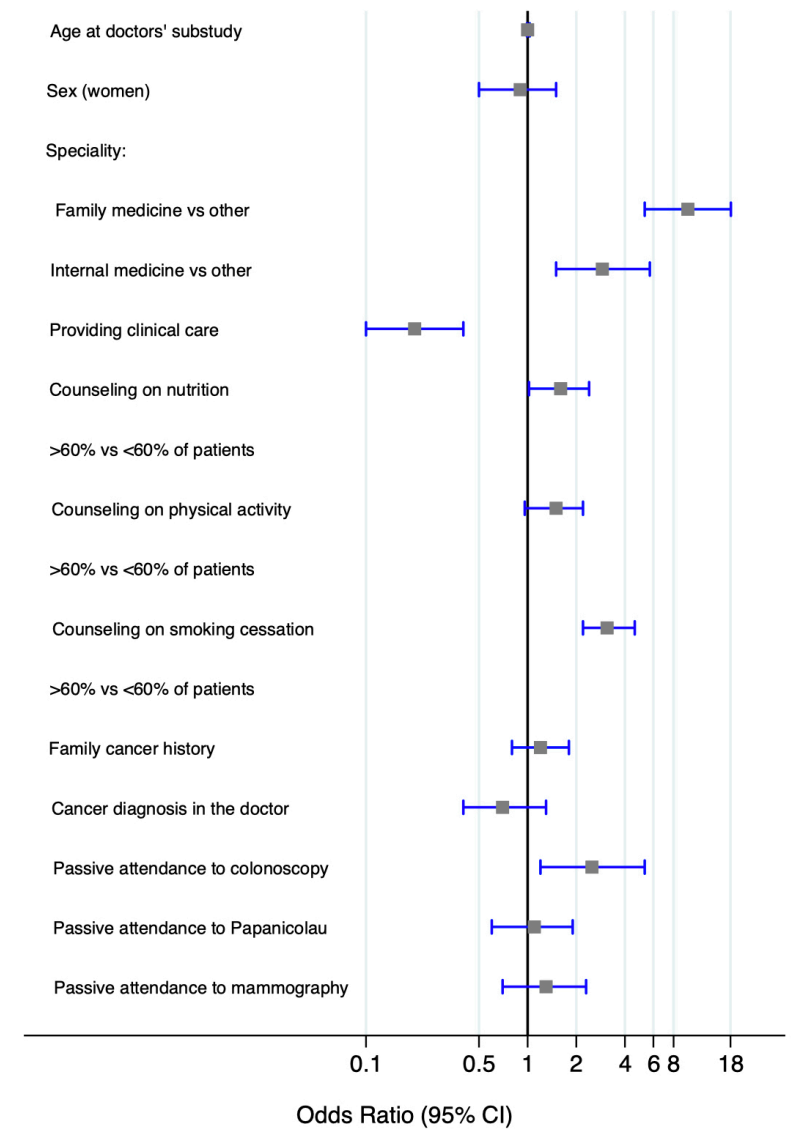

Figure 1 Doctors' baseline characteristics and clinical practice associated with cancer screening counselling $(n=890)$. multivariate logistic regression model including all variables in figure. For age, the ORs are calculated for each 10 years of increment.

is discouraged (D recommendation). Prostate cancer screening demonstrated a small potential benefit of reducing the odds of death from prostate cancer in some men; at the same time, many men will experience potential harms of screening, including false-positive results, overdiagnosis and overtreatment; notwithstanding, the most disquieting aspect is the treatment complications, which include incontinence and erectile dysfunction.

National Cancer Institute's Health Information National Trends Survey found that between 2012 and 2017, the trend in patient-reported physician-patient discussions about lung cancer screening decreased from $7 \%$ in 2012 to $4 \%$ in $2017 .{ }^{29}$ For lung cancer, as recently stated by the USPSTF in February 2020, the most effective primary preventive strategy is not starting smoking, as opposed to stopping smokers from smoking as soon as possible. Screening among those meeting criteria can reduce lung cancer mortality, but screening among those not meeting criteria can increase the harms associated with overdiagnosis and overtreatment. ${ }^{29} 30$ That is why, for this screening, patients and clinicians should consider the balance of benefits and harms on the basis of family history, race/ethnicity, comorbid medical conditions, etc. ${ }^{31}$ In our study, we did not distinguish if the physician discusses the harms and benefits with their patients or just recommends the screening.

Our study showed that cancer screening counselling was associated with the other preventive counselling, such as smoking cessation, exercise, weight control and alcohol consumption. Other authors have described a connection between primary care visits and different preventive measures. ${ }^{32}$ In January 2020, Huo et al published a study showing that among smokers undergoing lung cancer screening, $15 \%$ had not been counselled or did not remember having been counselled about smoking by providers. ${ }^{29}$ A qualitative study that asked physicians and lung cancer screened patients about cancer screening and smoking counselling found that they described little connection between counselling on both preventive measures. ${ }^{33}$ Between 2013 and 2015, Kenison et al carried out a study among patients who were already cancer survivors to compare the frequency of counselling on cancer screening and healthy lifestyle between different physicians and nurses, and found no differences between doctors and nurses in screening counselling, but nurses discussed lifestyle modification more frequently. ${ }^{34}$ A study published in 2019 that also analysed lifestyle counselling among cancer survivors found that $53 \%$ had been counselled on healthy diet, $49 \%$ on exercise, $28 \%$ on vegetable consumption and $17 \%$ on the three behaviours, while $85 \%$ of smokers had been counselled on smoking cessation. ${ }^{35}$ In this context, according to the WHO, around one-third of cancer-related deaths can be attributed to these modifiable risk factors. ${ }^{36}$ Also, nearly $40 \%$ of newly diagnosed cancers are avoidable, and cancer related to modifiable risk factors accounts for the largest share of this estimate. It is not surprising that physicians included in our study combine the counselling of primary and secondary preventions for cancer as it was shown that this strategy is both an effective and cost-effective way to fight against cancer. ${ }^{3}$

When we analysed the association between prescribing some kind of preventive medication such as blood pressure medication or aspirin, we found that doctors prescribing those drugs more frequently than their colleagues were more likely to counsel about any kind of cancer screening. In this context, a previous study conducted in this same sample of doctors found that prescribing practices were associated other forms of behavioural counselling. ${ }^{13}$

Our study showed that age or sex of the physician was not associated with counselling of screening cancer in general. These results are similar to those that Engler et al found in their study where no differences were found between male and female physicians regarding rating the cancer screening examination as useful or fairly useful, ${ }^{27}$ and Lofters et al found no differences between physicians' age and the counselling of cancer screening. ${ }^{37}$ Similarly, a recent systematic review also analysed the associations of physician characteristics with decisions regarding various common cancer screening tests. ${ }^{38}$ In accordance with our results, they found that women physicians were more 
likely to counsel about breast cancer screening but not about other cancer screening.

The findings of the present study can help in the design of strategies focused on the promotion of healthy lifestyles among physicians, as well as the development of medical education programmes that include more health education on prevention. This goal can be achieved by reinforcing the message towards physicians of becoming personal role models for their patients by incorporating these recommendations (healthy lifestyles and screening practices) into their own lives and preventive medicine practices. In conjunction, these measures will contribute to improve clinical practices and to promote healthier lifestyles and screening practices in their patients and thus, a lower incidence of disease in the population at large.

The present study has some limitations. First, changes in anthropometrics, sociodemographics and behaviours that may have occurred during the follow-up were not taken into account. Second, characteristics of patients who were counselled by the physicians included in the study where not collected. Admittedly, these characteristics might be a factor which could modify the frequency and the content of counselling. However, information about counselling was categorised as ' $0,<60 \%$ and $60 \%-100 \%$ ', thus including the majority of patients in the '60\%-100\%' category, which makes counselling less likely to be associated with patients' personal characteristics. Third, $14.3 \%$ of the physicians included in the study were not attending patients at study time; in that case, we asked what they would have done if they were attending.

In spite of the study limitations, this study has several strengths. First, our study evaluates the association between doctors' own lifestyle and clinical practice that can be associated with counselling patients on cancer screening, an association that has been scarcely explored in the literature. Another strength is that all physicians included come from the SUN study, a cohort that collects abundant information regarding lifestyles, and the occurrence of many chronic diseases.

In conclusion, we found that some lifestyle behaviours and particularly clinical practices among medical doctors are associated with cancer screening counselling. Physicians who counsel about healthy lifestyles are more prone to counsel about specific cancer screening interventions.

Acknowledgements We thank other members of the SUN Group: Alonso A, Álvarez-Álvarez I, Balaguer A, Barbagallo M, Barrientos I, Barrio-López MT, BasterraGortari FJ, Battezzati A, Bazal P, Benito S, Bertoli S, Bes-Rastrollo M, Beulen Y, Beunza JJ, Buil-Cosiales P, Canales M, Carmona L, Cervantes S, Cristobo C, de Irala J, de la 0 V, de la Rosa PA, Delgado-Rodríguez M, Díaz-Gutiérrez J, Díez Espino J, Domínguez L, Donat-Vargas C, Donazar M, Eguaras S, Fresán U, Galbete C, García-Arellano A, García López M, Gardeazábal I, Gea A, Gutiérrez- Bedmar M, Gomes-Domingos AL, Gómez-Donoso C, Gómez-Gracia E, Goñi E, Goñi L, Guillén F, Henríquez P, Hernández A, Hershey MS, Hidalgo-Santamaría M, Hu E, Lahortiga F, Leone A, Llorca J, López del Burgo C, Marí A, Marques I, Martí A, Martín Calvo N, Martín-Moreno JM, Martínez JA, Martínez-Lapiscina EH, Mendonça R, Menéndez C, Molendijk M, Molero P, Murphy K, Muñoz M, Núñez- Córdoba JM, Pajares R, Pano-Espinola 0, Papadaki A, Parletta N, Pérez de Ciriza P, Pérez Cornago A, Pérez de Rojas J, Pimenta AM, Pons J, Ramallal R, Razquin C, Romanos A, Ruano C, Ruiz L, Ruiz-Canela M, Ruiz Zambrana A, Salgado E, San Julián B, Sánchez D,
Sánchez-Bayona R, Sánchez-Tainta A, Sánchez-Villegas A, Santiago S, Sayón-Orea C, Schlatter J, Serrano-Martinez M, Toledo E, Toledo J, Tortosa A, Valencia F, Vázquez Z, Zarnowiecki D and Zazpe I. We especially thank all participants in the SUN cohort for their long-standing and enthusiastic collaboration and our advisors from Harvard T.H. Chan School of Public Health, Walter Willett, Alberto Ascherio, Frank B Hu and Meir J Stampfer, who helped us design the SUN Project, the PREDIMED study and the PREDIMED-PLUS ongoing trial.

Contributors Conceptualisation: SC, AF-M, ET and MAM-G; methodology: SC, ET and MAM-G; data curation and writing (original draft preparation): SC and CS-0; supervision: ET and MAM-G; writing, reviewing and editing: SK, AF-M, CdIF-A, AR-C, ET and MAM-G; guarantor: CS-0 and SC.

Funding The SUN Project has received funding from the Spanish GovernmentInstituto de Salud Carlos III and the European Regional Development Fund (RD 06/0045, CIBER-0BN, grants Pl10/02658, Pl10/02293, Pl13/00615, Pl14/01668, PI14/01798, PI14/01764, PI17/01795 and G03/140), the Navarra Regional Government (27/2011, 45/2011 and 122/2014) and the University of Navarra. The funding sources had no involvement in the study design; in data collection, analysis, or interpretation of data; in the writing of the report; or in the decision to submit the paper for publication.

Competing interests None declared.

Patient consent for publication Not applicable.

Ethics approval This study involves human participants and was approved by University of Navarra Ethics Committee (091/2008). Participants were informed that they could refuse to participate or withdraw at any time without reprisal, according to the Declaration of Helsinki. The participants gave informed consent to participate in the study before taking part.

Provenance and peer review Not commissioned; externally peer reviewed.

Data availability statement Data are available upon reasonable request. Information on data availability can be checked at https://www.unav.edu/en/web/ departamento-de-medicina-preventiva-y-salud-publica/proyecto-sun/informacionpara-investigadores.

Supplemental material This content has been supplied by the author(s). It has not been vetted by BMJ Publishing Group Limited (BMJ) and may not have been peer-reviewed. Any opinions or recommendations discussed are solely those of the author(s) and are not endorsed by BMJ. BMJ disclaims all liability and responsibility arising from any reliance placed on the content. Where the content includes any translated material, BMJ does not warrant the accuracy and reliability of the translations (including but not limited to local regulations, clinical guidelines, terminology, drug names and drug dosages), and is not responsible for any error and/or omissions arising from translation and adaptation or otherwise.

Open access This is an open access article distributed in accordance with the Creative Commons Attribution Non Commercial (CC BY-NC 4.0) license, which permits others to distribute, remix, adapt, build upon this work non-commercially, and license their derivative works on different terms, provided the original work is properly cited, appropriate credit is given, any changes made indicated, and the use is non-commercial. See: http://creativecommons.org/licenses/by-nc/4.0/.

\section{ORCID iDs}

Silvia Carlos http://orcid.org/0000-0002-4968-7080

Alejandro Fernández-Montero http://orcid.org/0000-0002-8741-7401

\section{REFERENCES}

1 Fitzmaurice C, Abate D, et al, Global Burden of Disease Cancer Collaboration. Global, regional, and National cancer incidence, mortality, years of life lost, years lived with disability, and DisabilityAdjusted life-years for 29 cancer groups, 1990 to 2017: a systematic analysis for the global burden of disease study. JAMA Oncol 2019;5:1749-68.

2 Ferlay J, Colombet M, Soerjomataram I, et al. Estimating the global cancer incidence and mortality in 2018: GLOBOCAN sources and methods. Int J Cancer 2019;144:1941-53.

3 Vineis P, Wild CP. Global cancer patterns: causes and prevention. Lancet 2014;383:549-57.

4 Gøtzsche PC. Commentary: screening: a seductive paradigm that has generally failed us. Int J Epidemiol 2015;44:278-80.

5 Taylor P. Commentary: tempering expectations of screening: what is the most authoritative advice we can give, given the data that we have? Int J Epidemiol 2015;44:280-2. 
6 International Agency for Research on Cancer. 12 ways to reduce your cancer risk. Lyon, France: European Code Against Cancer, 2016.

7 Wender RC. Cancer screening and prevention in primary care. obstacles for physicians. Cancer 1993;72:1093-9.

8 Lynn B, Hatry A, Burnett C, et al. Identifying primary care physicians continuing education needs by examining clinical practices, attitudes, and barriers to screening across multiple cancers. $J$ Cancer Educ 2018;33:1255-62.

9 Carlos S, De La Fuente-Arrillaga C, Bes-Rastrollo M, et al. Mediterranean diet and health outcomes in the sun cohort. Nutrients 2018;10:439-24.

10 Seguí-Gómez M, de la Fuente C, Vázquez Z, et al. Cohort profile: the 'Seguimiento Universidad de Navarra' (SUN) study. Int J Epidemiol 2006;35:1417-22.

11 Martínez-González MA, Sanchez-Villegas A, De Irala J. Mediterranean diet and stroke: objectives and design of the sun project. Seguimiento Universidad de Navarra. Nutr Neurosci 2002;5:65-73.

12 Leone A, Martínez-González Miguel Á, Martin-Gorgojo A, et al. Mediterranean diet, dietary approaches to stop hypertension, and Pro-vegetarian dietary pattern in relation to the risk of basal cell carcinoma: a nested case-control study within the Seguimiento Universidad de Navarra (sun) cohort. Am J Clin Nutr 2020;112:364-72.

13 Carlos S, Rico-Campà A, de la Fuente-Arrillaga $\mathrm{C}$, et al. Do healthy doctors deliver better messages of health promotion to their patients?: data from the sun cohort study. Eur $J$ Public Health 2020;30:438-44.

14 Martín-Moreno JM, Boyle P, Gorgojo L, et al. Development and validation of a food frequency questionnaire in Spain. Int $J$ Epidemiol 1993;22:512-9.

15 de la Fuente-Arrillaga C, Ruiz ZV, Bes-Rastrollo M, et al. Reproducibility of an FFQ validated in Spain. Public Health Nutr 2010;13:1364-72.

16 Fernández-Ballart JD, Piñol JL, Zazpe I, et al. Relative validity of a semi-quantitative food-frequency questionnaire in an elderly Mediterranean population of Spain. Br J Nutr 2010;103:1808-16.

17 Siembida EJ, Radhakrishnan A, Nowak SA, et al. Linking reminders and physician breast cancer screening recommendations: results from a national survey. JCO Clin Cancer Inform 2017;1:1-10.

18 Radhakrishnan A, Nowak SA, Parker AM, et al. Linking physician attitudes to their breast cancer screening practices: a survey of US primary care providers and gynecologists. Prev Med 2018;107:90-102.

19 Grady D, Redberg RF. Physician adherence to breast cancer screening recommendations. JAMA Intern Med 2017;177:763-4.

20 U.S. Preventive Services Task Force. Uspstf $A$ and $B$ recommendations, 2019.

21 Council of the European Union. Council recommendation of 2 December 2003 on cancer screening (2003/878/EC), 2003.

22 Wee CC, McCarthy EP, Phillips RS. Factors associated with colon cancer screening: the role of patient factors and physician counseling. Prev Med 2005;41:23-9.
23 ENSE. Ministerio de Sanidad Consumo Y Bienestar social. Madrid, España: Detección Precoz de cáncer, 2017.

24 Hsiang EY, Mehta SJ, Small DS, et al. Association of primary care clinic appointment time with clinician ordering and patient completion of breast and colorectal cancer screening. JAMA Netw Open 2019;2:e193403.

25 Selby K, Bartlett-Esquilant G, Cornuz J. Personalized cancer screening: helping primary care rise to the challenge. Public Health Rev 2018:39:1-8.

26 Lieberman D, Ladabaum U, Cruz-Correa M, et al. Screening for colorectal cancer and evolving issues for physicians and patients: a review. JAMA 2016;316:2135-45.

27 Engler J, Dahlhaus A, Güthlin C. The readiness of German GPs to recommend and conduct cancer screening is associated with patient-physician gender concordance. Results of a survey. Eur $J$ Gen Pract 2017;23:11-19.

28 Kepka D, Smith A, Zeruto C, et al. Is provider type associated with cancer screening and prevention: advanced practice registered nurses, physician assistants, and physicians. BMC Cancer 2014;14:1-9.

29 Huo J, Chung TH, Kim B, et al. Provider-Patient discussions about smoking and the impact of lung cancer screening guidelines: NHIS 2011-2015. J Gen Intern Med 2020;35:43-50.

30 Richards TB, Soman A, Thomas CC, et al. Screening for Lung Cancer - 10 States, 2017. MMWR Morb Mortal Wkly Rep 2020;69:201-6.

31 Grossman DC, Curry SJ, Owens DK. Screening for prostate cancer USPreventive servicestaskforcerecommendation statement. JAMA J Am Med Assoc 2018;319:1901-13.

32 Goold SD, Tipirneni R, Chang T, et al. Primary care, health promotion, and disease prevention with Michigan Medicaid expansion. $J$ Gen Intern Med 2020;35:800-7.

33 Kathuria H, Koppelman E, Borrelli B. Patient-Physician discussions on lung cancer screening: a missed Teachable moment to promote smoking cessation. Nicotine Tob Res 2018;35:1-9.

34 Kenison TC, Silverman P, Sustin M, et al. Differences between nurse practitioner and physician care providers on rates of secondary cancer screening and discussion of lifestyle changes among breast cancer survivors. J Cancer Surviv 2015;9:223-9.

35 Halilova KI, Pisu M, Azuero A, et al. Healthy lifestyle discussions between healthcare providers and older cancer survivors: data from 12 cancer centers in the southeastern United States. Cancer Med 2019;8:7123-32.

36 Danaei G, Vander Hoorn S, Lopez AD, et al. Causes of cancer in the world: comparative risk assessment of nine behavioural and environmental risk factors. Lancet 2005;366:1784-93.

37 Lofters AK, Ng R, Lobb R. Primary care physician characteristics associated with cancer screening: a retrospective cohort study in Ontario, Canada. Cancer Med 2015;4:212-23.

38 Neugut Al, MacLean SA, Dai WF, et al. Physician characteristics and decisions regarding cancer screening: a systematic review. Popul Health Manag 2019;22:48-62. 